\title{
Analisis Faktor-Faktor yang Memengaruhi Tingkat Pertumbuhan Ekonomi pada 20 Negara OKI Tahun 2009-2013
}

\author{
Risna Nurul Insani \\ Program Studi Ilmu Ekonomi Islam \\ Sekolah Tinggi Ekonomi Islam Tazkia, Bogor \\ Indra \\ Program Studi Ilmu Ekonomi Islam \\ Sekolah Tinggi Ekonomi Islam Tazkia, Bogor \\ Email: Stei@tazkia.ac.id
}

\begin{abstract}
This study aims to analyze factors that affect economic growth in OIC member countries by using neo-classical model of economic growth and economic growth of Ibn Khaldun. The model consists of five variables, namely: labor, capital accumulation, agriculture, trade, and inflation. This study was using regression analysis of panel data with the object 20 OIC member countries (Afghanistan, Bangladesh, Mozambique, Togo, Uzbekistan, Indonesia, Nigeria, Pakistan, Tunisia, Jordan, Kazakhstan, Lebanon, Malaysia, Algeria, Turkey, Brunei, Kuwait, Oman, Arabia, and United Arab Emirates), from 2009 to 2013. The results showed that four of the five variables used to significantly affect the economic growth in OIC countries is variable labor, capital accumulation, agriculture, and trade, while inflation variable has no significant effect. From this study it can be concluded that not all the variables significantly influence economic growth in OIC countries.
\end{abstract}

Keywords: Economic Growth, The Organization of Islamic Cooperation, Panel Data

\begin{abstract}
Abstrak
Penelitian ini bertujuan untuk menganalisis faktor-faktor yang mempengaruhi pertumbuhan ekonomi di negara-negara anggota OKI dengan menggunakan model neo-klasik pertumbuhan ekonomi dan pertumbuhan ekonomi Ibnu Khaldun. Model ini terdiri dari lima variabel, yaitu: tenaga kerja, akumulasi
\end{abstract}


modal, pertanian, perdagangan, dan inflasi. Penelitian ini menggunakan analisis regresi data panel dengan negara-negara anggota OKI objek 20 (Afghanistan, Bangladesh, Mozambik, Togo, Uzbekistan, Indonesia, Nigeria, Pakistan, Tunisia, Yordania, Kazakhstan, Lebanon, Malaysia, Aljazair, Turki, Brunei, Kuwait, Oman, Saudi, dan Uni Emirat Arab), dari 2009 ke 2013. Hasil penelitian menunjukkan bahwa empat dari lima variabel yang digunakan untuk secara signifikan mempengaruhi pertumbuhan ekonomi di negaranegara OKI adalah tenaga kerja variabel, akumulasi modal, pertanian, dan perdagangan, sedangkan variabel inflasi tidak berpengaruh signifikan. Dari penelitian ini dapat disimpulkan bahwa tidak semua variabel berpengaruh signifikan terhadap pertumbuhan ekonomi di negara-negara OKI.

Kata Kunci: Pertumbuhan ekonomi, OKI, data panel

\section{Pendahuluan}

Sejak ilmu ekonomi berkembang di dunia, masalah pertumbuhan ekonomi telah banyak diteliti oleh para ilmuwan barat maupun ilmuwan muslim yang menghasilkan banyak teori dan aliran ekonomi. Aliran ekonom neo klasik lebih menekankan pertumbuhan ekonomi pada penyediaan tenaga kerja, stok modal, dan perubahan teknologi (Sutawijaya, 2007). Pendekatan ini didasarkan pada asumsi bahwa pasar dapat mengalokasikan sumber daya secara efisien. Sedangkan menurut ilmuwan muslim diantaranya yaitu Ibnu Khaldun berpendapat bahwa sektor yang berpengaruh penting kepada pertumbuhan ekonomi yaitu sektor pertanian, sektor industri, dan sektor perdagangan (Beik, 2008) .

Berawal dari dibentuknya Organisasi Kerjasama Islam (OKI) pada tanggal 25 September 1969 yang saat ini beranggotakan 57 negara. OKI merupakan organisasi antar-pemerintah kedua setelah PPB yang tersebar di empat benua. Tujuan awal dari pembentukan OKI tersebut ialah untuk menjaga dan melindungi kepentingan dunia Islam dalam semangat mempromosikan perdamaian (www.kemlu.go.id). Namun dalam perkembangannya, pada Konferensi Tingkat Tinggi (KTT) ke-3 bulan Desember 2005 negara-negara yang tergabung dalam OKI menyusun blue print yang disebut dengan Ten-Year Program of Action. 
Kontribusi OKI pada bidang ekonomi yaitu bertujuan untuk memperkuat kerjasama ekonomi dan perdagangan dalam rangka mencapai integrasi ekonomi yang mengarah kepada pembentukan Islamic Common Market. Maka dibentuklah Economic and Commercial Cooperation of the OIC (COMCEC) pada Islamic Summit Conference pada Januari 1981. COMCEC menindaklanjuti pelaksanaan resolusi di bidang ekonomi dan bidang perdagangan, mengeksplorasi kemungkinan cara memperkuat kerjasama antar negara-negara anggota, dan mempersiapkan program yang mampu meningkatkan kapasitas ekonomi di daerah-daerah (www.sesric.org).

Namun hingga saat ini peran OKI khususnya dalam bidang perdagangan belum begitu terlihat kontribusinya terhadap perekonomian. Hal ini dibuktikan dengan data SESRIC pada tahun 2011, 57 negara OKI menyumbang 22,8 persen dari total penduduk dunia, namun persentase PDB negaranegara OKI yang dihasilkan hanya sebesar 10,9 persen dari total PDB seluruh dunia. Ketimpangan tersebut dapat disebabkan oleh karakteristik ekonomi negara anggota OKI yang berbeda, antara lain beberapa negara OKI dikategorikan sebagai negara berpenghasilan tinggi, sementara yang lainnya dikategorikan sebagai negara berpenghasilan rendah (Alpay et. Al., 2011).

\section{Tujuan Penelitian}

Penelitian ini bertujuan untuk melihat peran OKI dalam pertumbuhan ekonomi dan faktor-faktor yang mempengaruhinya dengan menggunakan dua pendekatan konsep pertumbuhan ekonomi yaitu pertumbuhan ekonomi neo-klasik dan pertumbuhan ekonomi perspektif Ibnu Khaldun. Objek studi yang digunakan yaitu negara OKI dikarenakan mayoritas penduduknya yang beragama Islam dan memiliki tingkat income yang berbeda-beda pada tiap negara anggotanya. Variabel yang diambil dari teori pertumbuhan ekonomi neo klasik antara lain tenaga kerja dan akumulasi modal, sedangkan dari pertumbuhan ekonomi perspektif Ibnu Khaldun menggunakan variabel pertanian dan perdagangan.

Sedangkan penelitian terdahulu yang berkaitan dengan penelitian kali ini adalah: Hasan et.al (2011) yang meneliti hubungan antara financial development dan pertumbuhan ekonomi di Negara-negara OKI. Kemudian 
Yusuf et.al (2011) tentang disparitas pelaksanaan kegiatan ekonomi di negaranegara OKI yang menyebabkan porsi keuntungan produktifitas berkurang. Ashgar et.al (2011) tentang Foreign Direct Investment dan Pertumbuhan Ekonomi saling terkointegrasi. Mohammad (2011) perbandingan performa Variabel Makroekonomi di Negara-negara OKI dan Cheong (2003) tentang hubungan jangka panjang pada fungsi agregat permintaan impor.

\section{Metodologi Penelitian}

Penelitian ini menggunakan data sekunder. Jenis data yang digunakan dalam penelitian ini adalah jenis data sekunder, yaitu data penelitian yang diperoleh secara tidak langsung atau melalui media perantara. Analisis dalam penelitan ini menggunakan data sekunder yang dikumpulkan dari beberapa sumber yang berupa data panel dengan time series tahunan dari tahun 20092013 dan cross section 20 negara OKI antara lain low income countryyaitu Afghanistan, Bangladesh, Mozambik, Togo, Uzbekistan; lower-middle incomecountry yaitu Indonesia, Nigeria, Pakistan, Tunisia, Yordania; uppermiddle incomecountry yaitu Kazakhstan, Lebanon, Malaysia, Algeria, Turki; serta high income country yaitu Brunei, Kuwait, Oman, Saudi, dan Uni Emirat Arab. Data diperoleh dari website-website resmi seperti World Bank, Organisation of Islamic Cooperation (OIC-OCI), Economic and Social Research and Training Centre for Islamic Countries (SESRIC), dan SESRIC BASEIND Database.

Penelitian ini menggunakan variabel-variabel yang mempengaruhi pertumbuhan ekonomi negara OKI yaitu sumber daya manusia, sumber daya modal, agrikultur, perdagangan, dan inflasi dengan bentuk model persamaan sebagai berikut:

$\mathrm{PDB}_{\mathrm{it}}=\beta_{0}+\beta_{1} \mathrm{TLF}_{\mathrm{it}}+\beta_{2} \mathrm{FDI}_{\mathrm{it}}+\beta_{3} \mathrm{PDBp}_{\mathrm{it}}+\beta_{4} \mathrm{DKP}_{\mathrm{it}}+\beta_{5} \mathrm{INF}_{\mathrm{it}}+\mu_{\mathrm{it} . .}$

Di mana:

$\mathrm{PDB} \quad=\mathrm{PDB}$ riil

tlf $\quad=$ Total Labor Force

FDI $=$ Foreign Direct Investment

PDBp = PDB Sektor Pertanian 
$\mathrm{dkp}=$ Derajat Keterbukaan Perdagangan $\frac{X+m}{G D P}$

$\mathrm{INF} \quad=$ Inflasi (variabel kontrol)

$\alpha_{0} \quad=$ Intercept

$\alpha_{1}, \alpha_{2}, \alpha_{3}, \ldots, \alpha_{5}=$ Koefisien regresi variabel bebas

$\mu_{\mathrm{it}} \quad=$ Komponen error di waktu $\mathrm{t}$ untuk unit cross section $\mathrm{i}$

$\mathrm{i} \quad=1,2,3, \ldots, 20$ (data cross-section, 20 Negara OKI)

$\mathrm{t} \quad=1,2,3,4,5$ (data time-series, tahun 2010-2013)

\section{Hasil dan Pembahasan}

\section{Deskripsi Objek Penelitian}

Penelitian ini menggunakan 20 sampel negara anggota OKI yang dijelaskan lengkap dengan keterangan tambahan berupa profil singkat masing-masing negara dalam tabel berikut:

Tabel 1

Profil Singkat 20 Negara OKI

\begin{tabular}{|c|c|c|c|c|c|}
\hline Nama Negara & Ibukota & Regional & Mata Uang & Bahasa & $\begin{array}{l}\text { Kategori } \\
\text { Income }\end{array}$ \\
\hline Afghanistan & Kabul & Asia Selatan & $\begin{array}{l}\text { Afghan } \\
\text { Afghani }\end{array}$ & $\begin{array}{l}\text { Pastho, } \\
\text { Dari }\end{array}$ & Low \\
\hline Algeria & Algiers & Afrika Utara & Dinar Algeria & Arab & $\begin{array}{l}\text { Upper } \\
\text { Middle }\end{array}$ \\
\hline Arab Saudi & Riyadh & Timur Tengah & Riyal & Arab & High \\
\hline Bahrain & Manama & Timur Tengah & $\begin{array}{l}\text { Dinar } \\
\text { Bahrain }\end{array}$ & Arab & High \\
\hline Bangladesh & Dhaka & Asia Selatan & Taka & Bengali & Low \\
\hline Brunei & $\begin{array}{l}\text { Bandar Seri } \\
\text { Begawan }\end{array}$ & $\begin{array}{l}\text { Asia } \\
\text { Tenggara }\end{array}$ & Dollar Brunei & Melayu & High \\
\hline Indonesia & Jakarta & $\begin{array}{l}\text { Asia } \\
\text { Tenggara }\end{array}$ & Rupiah & Indonesia & $\begin{array}{l}\text { Lower } \\
\text { Middle }\end{array}$ \\
\hline Kazakhstan & Astana & Asia Tengah & Tenge & Kazakh & $\begin{array}{l}\text { Upper } \\
\text { Middle }\end{array}$ \\
\hline Kuwait & Kuwait & Timur Tengah & Dinar Kuwait & Arab & High \\
\hline Lebanon & Beirut & Timur Tengah & $\begin{array}{l}\text { Lebanon } \\
\text { Pounds }\end{array}$ & Arab & $\begin{array}{l}\text { Upper } \\
\text { Middle }\end{array}$ \\
\hline Malaysia & Kuala Lumpur & $\begin{array}{l}\text { Asia } \\
\text { Tenggara }\end{array}$ & Ringgit & Melayu & $\begin{array}{l}\text { Upper } \\
\text { Middle }\end{array}$ \\
\hline Mozambique & Maputo & $\begin{array}{l}\text { Afrika } \\
\text { Tenggara }\end{array}$ & Metical & Portugis & Low \\
\hline
\end{tabular}




\begin{tabular}{|llllll|}
\hline Nigeria & Abuja & Afrika Barat & Naira & Inggris & $\begin{array}{l}\text { Lower } \\
\text { Middle }\end{array}$ \\
\hline Pakistan & Islamabad & Asia Selatan & $\begin{array}{l}\text { Rupee } \\
\text { Pakistan }\end{array}$ & Punjabi & $\begin{array}{l}\text { Lower } \\
\text { Middle }\end{array}$ \\
\hline Togo & Lomé & Afrika Barat & Franc & Perancis & Low \\
\hline Tunisia & Tunis & Afrika Utara & Dinar Tunisia & Arab & $\begin{array}{l}\text { Lower } \\
\text { Middle }\end{array}$ \\
\hline Turki & Ankara & Eurasia & Lira & Turki & $\begin{array}{l}\text { Upper } \\
\text { Middle }\end{array}$ \\
\hline UEA & Abu Dhabi & Timur Tengah & Dirham & Arab & High \\
\hline Uzbekistan & Tashkent & Asia Tengah & Som & Uzbek & Low \\
\hline Yordania & Amman & Timur Tengah & $\begin{array}{l}\text { Dinar } \\
\text { Yordania }\end{array}$ & Arab & $\begin{array}{l}\text { Lower } \\
\text { Middle }\end{array}$ \\
\hline
\end{tabular}

Sumber: World Bank, OIC, Heritage Foundation

\section{Deskripsi Variabel Penelitian}

Berikut ini akan dipaparkan data dari SESRIC BASEIND Database yang ada berhubungan dengan faktor-faktor yang mempengaruhi pertumbuhan ekonomi antara lain GDP per kapita, labor participation rate, FDI, GDP sektor pertanian, dan total ekspor impor di negara OKI.

\section{A. Pert umbuhan Ekonomi}

Penelitian ini menggunakan GDP harga konstan (riil) sebagai proksi dari pertumbuhan ekonomi. GDP harga konstan merupakan Jumlah dari nilai tambah bruto oleh semua produsen warga dalam perekonomian ditambah pajak produk dan dikurangi subsidi tidak termasuk dalam nilai produk (World Bank). Data berikut merupakan rata-rata GDP per kapita negara OKI dari tahun 2009 sampai dengan tahun 2013 yang diolah menggunakan microsoft excel.

Gambar 2.

Rata-Rata GDP Per Kapita Negara OKI (2009-2013)

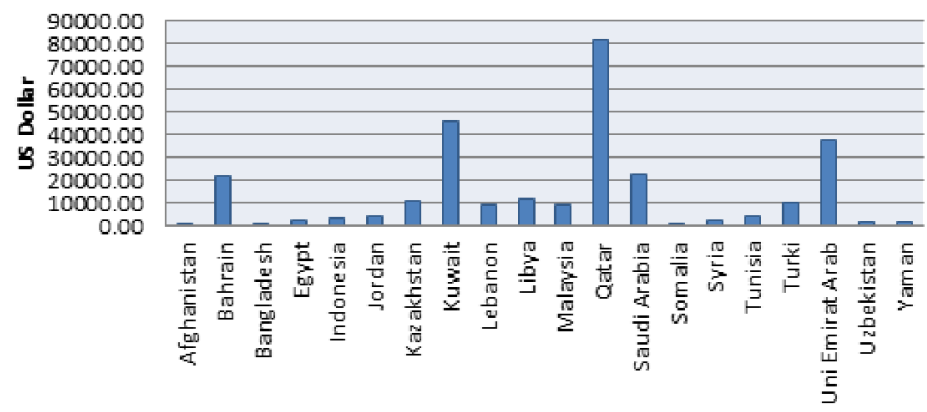

Sumber: SESRIC BASEIND Database (diolah) 
Pada gambar 1, negara dengan rata-rataGDPper kapita tertinggi ditempati oleh Qatar sebesar 81776 USD per tahunnya. Di sisi lain rata-rata gdp per kapita terendah terjadi pada negara Somalia sebesar 138 USD per tahun.Negara lain yang memiliki rata-rata GDP per kapita yang rendah yaitu Afganistan sebesar 620 USD per tahun dan Bangladesh sebesar 813 USD per tahun. Sedangkan negara dengan rata-rata GDP per kapita tertinggi antara lain Kuwait, Uni Emirat Arab, Arab Saudi dan Bahrain dengan angka diatas 10 ribu USD per tahun. Dari data tersebut dapat disimpulkan bahwa masih terdapat banyak negara yang harus melakukan upaya yang lebih maksimal agar mampu menaikkan rata-rata GDP per kapita di negaranya terutama untuk negara dengan rata-rata GDP per kapita di bawah 10 ribu USD.

Tenaga kerja menurut World Bank ialah jumlah angkatan kerja terdiri dari orang usia 15 dan lebih tua yang memenuhi definisi ILO dari populasi yang aktif secara ekonomi. Dalam penelitian ini penulis menggunakan variabel labor force total sebagai proksi dari tenaga kerja. Berikut ini merupakan overview dari ketenagakerjaan negara OKI menggunakan data Labor Participation Rate.

Gambar 3

Rata-Rata Labor Participation Rate Negara OKI (2009-2013)

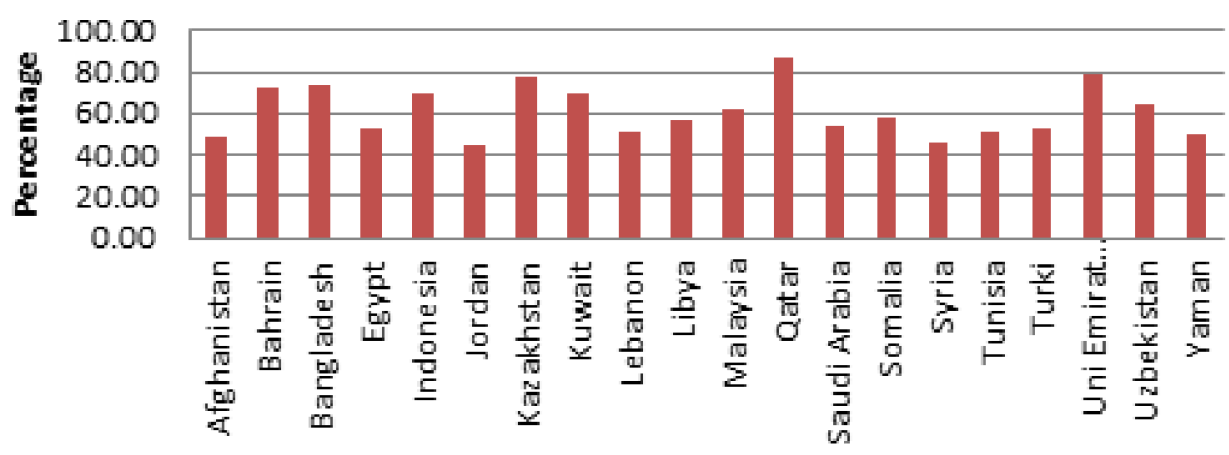

Sumber: SESRIC BASEIND Database (diolah)

Untuk data Labor Participation Rate (LPR), negara dengan ratarataLPR tertinggi yaitu Qatar sebesar 87,14 \%. Selain itu Uni Emirat Arab, Kazakhstan, Bangladesh dan Bahrain yang berada pada angka 70\%. Sedangkan negara yang rata-rata LPR terendah yaitu Yordania sebesar 44\%. Negara lainnya yang berada pada angka di bawah 50 \% yaitu Syria, 
Afghanistan, dan Yaman. Hal ini menunjukkan bahwa negara dengan income yang tinggi memiliki hubungan dengan tingkat LPR dalam data ini contohnya negara Yordania.

\section{Sumber Daya Modal}

Untuk variabel sumber daya modal, penulis menggunakan data Foreign Direct Investment (FDI) sebagai proksinya. FDI adalah jumlah modal ekuitas, reinvestasi pendapatan, modal jangka panjang lainnya, dan modal jangka pendek seperti yang ditunjukkan pada neraca pembayaran (World Bank). Di bawah ini terdapat hasil rata-rata FDI 20 negara OKI dari tahun 2009 hingga tahun 2013.

Gambar 4

Rata-Rata FDI Negara OKI (2009-2013)

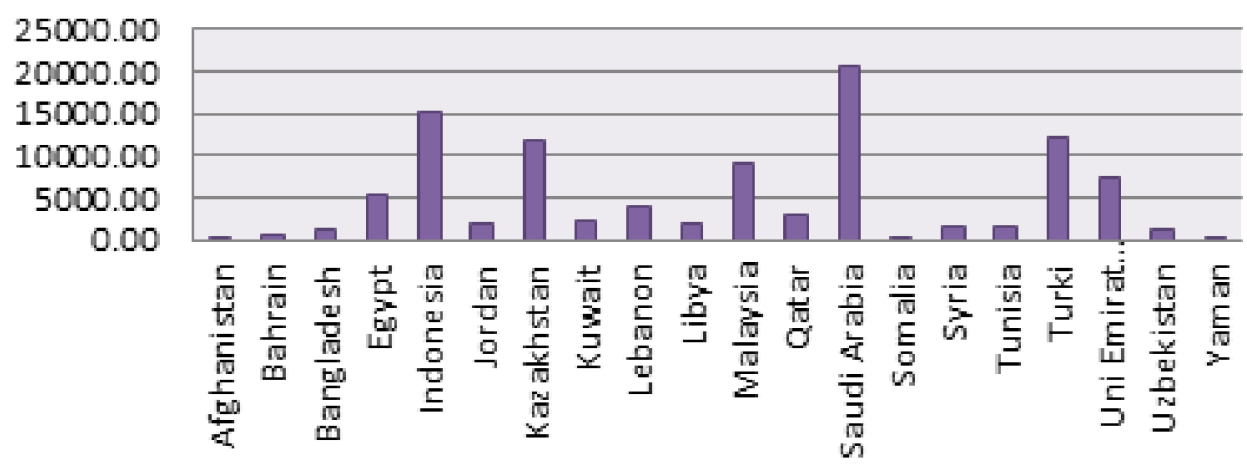

Sumber: SESRIC BASEIND Database (diolah)

Salah satu faktor pertumbuhan ekonomi yaitu tersedianya sumber daya modal yang pada penelitian ini menggunakan indikator Foreign Direct Investment (FDI). Negara dengan rata-rata FDI terendah yaitu negara Afghanistan hanya sebesar 106,7 USD disusul oleh Somalia sebesar 107,29 USD. Sedangkan negara dengan rata-rata FDI yaitu Arab Saudi sebesar 20695,7 USD. Selanjutnya negara dengan nilai rata-rata FDI lebih dari 10 ribu dollar antara lain Indonesia, Turki, dan Kazakhstan. 


\section{Pertanian}

Gambar 5

Rata-Rata Share GDP Pertanian Negara OKI (2009-2013)

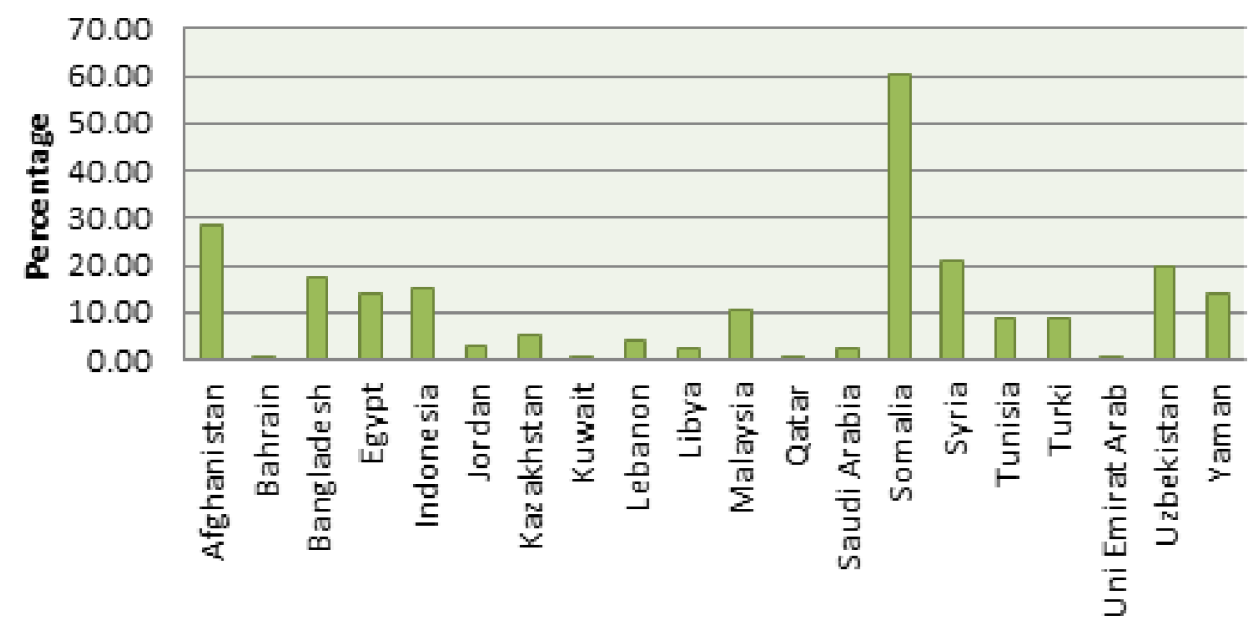

Sumber: SESRIC BASEIND Database (diolah)

Variabel pertanian menggunakan nilai tambah (value added) sebagai proksinya. Menurut World Bank, nilai tambah adalah output bersih dari sektor pertanian setelah menambahkan semua output dan mengurangi input antara. Berikut ini merupakan nilai rata-rata share GDP pertanian negara OKI tahun 2009 sampai dengan tahun 2013.

Untuk sektor pertanian, pada penelitian ini menggunakan data GDP sektor pertanian menunjukkan negara dengan rata-rata GDP sektor pertanian tertinggi yaitu negara Somalia sebesar 37\% . Sedangkan negara dengan ratarata-GDP sektor pertanian yang rendah yaitu Qatar sebesar 0,1\% disusul oleh Bahrain sebesar 0,3\%, Kuwait sebesar 0,34\%, dan Uni Emirat Arab sebesar $0,76 \%$. Dari data tersebut dapat dilihat bahwa sebagian negara timur tengah memiliki nilai rata-rata GDP sektor pertanian di bawah $1 \%$. Hal ini dapat disebabkan oleh keadaan tanahnya yang cenderung tandus. 


\section{Perdagangan}

\section{Gambar 6}

Rata-Rata Total Ekspor Impor Negara OKI (2009-2013)

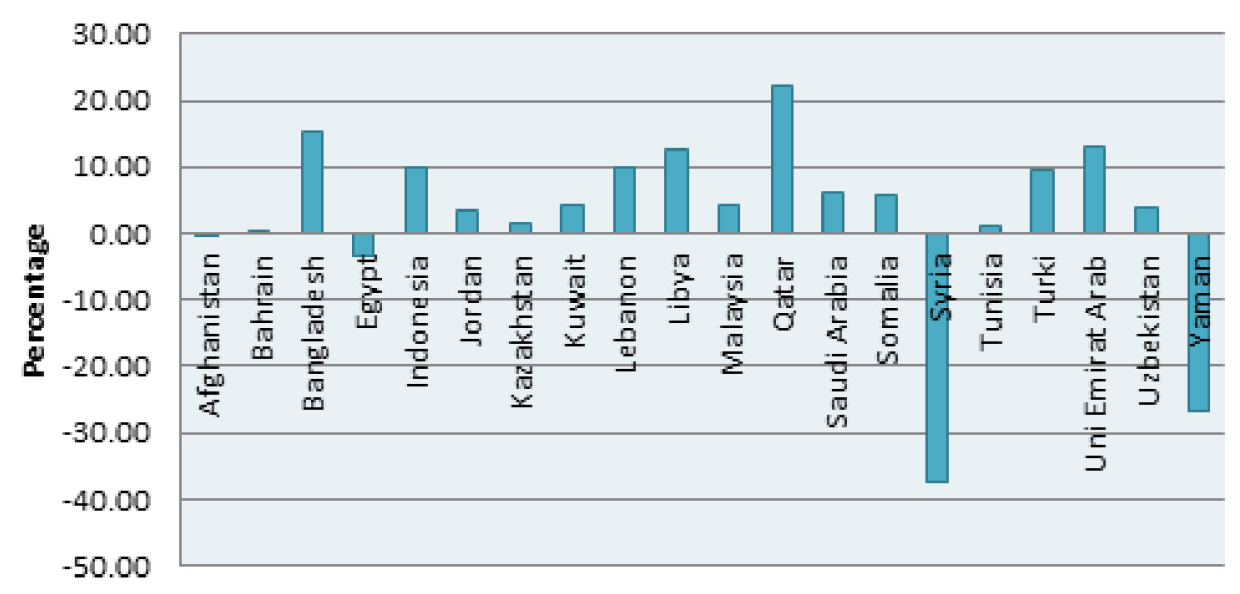

Sumber: SESRIC BASEIND Database (diolah)

Variabel yang terakhir yaitu sektor perdagangan yang menggunakan rata- rata total ekspor impor menunjukkan angka tertinggi yaitu negara Qatar sebesar 22,06\% dan Bangladesh berada di tempat kedua sebesar 15,38\%. Sedangkan negara dengan rata-rata total ekspor impor yang rendah yaitu Syria sebesar $-37,29 \%$ dan Yaman sebesar -26,815. Indikator lain yang dapat digunakan untuk mengukur perdagangan ialah derajat keterbukaan perdagangan.

\section{Hasil estimasi model}

Pada bagian ini akan disajikan hasil estimasi koefisien model regresi data panel yang merupakan model yang digunakan untuk mengkaji faktorfaktor yang mempengaruhi pertumbuhan ekonomi 20 negara anggota OKI. Berdasarkan tabel 3, koefisien estimasi yang disajikan merupakan hasil dari empat metode estimasi yakni PLS, FEM, REM, dan GLS. Penggunaan beberapa metode estimasi ini diharapkan dapat menunjukkan variasi hasil estimasi, melihat kebaikan model, serta validitas di antara berbagai metode estimasi yang digunakan. 
Secara umum, ke-empat metode estimasi yang digunakan menunjukkan hasil yang cukup baik. Hal ini terlihat dari tingkat signifikansi dan tanda koefisien estimasi yang dihasilkan dari model. Dalam empat metode estimasi yang digunakan, terlihat bahwa model REM lebih dipilih dibandingkan dua metode estimasi lainnya, yakni PLS dan FEM. Hal ini tercermin dari nilai statistik uji Hausman yang tidak signifikan pada taraf nyata 1 persen. Hasil uji Chow mengindikasikan bahwa model FEMebih dipilih dibandingkan PLS, sedangkan hasil uji Hausman menandakan bahwa model REMlebih dipilih daripada FEM.

Namun, hasil estimasi yang dihasilkan oleh pendekatan REM masih mengalami gejala autokorelasi. Hal ini dapat ditunjukkan oleh nilai statistik uji wooldridge test for autocorrelation in panel data yang signifikan pada taraf nyata 1 persen. Selain itu, model panel data yang diestimasi dengan pendekatan REM masih mengalami gejala heteroskedastis. Hal ini terlihat dari nilai statistik uji wald test for groupwise heteroskedasticity yang signifikan pada taraf nyata 1 persen. Adapun hasil ekonometrika dari penelitian ini telah dirangkum dalam tabel berikut ini.

Gambar 6

Tabel Hasil Ekonometrika

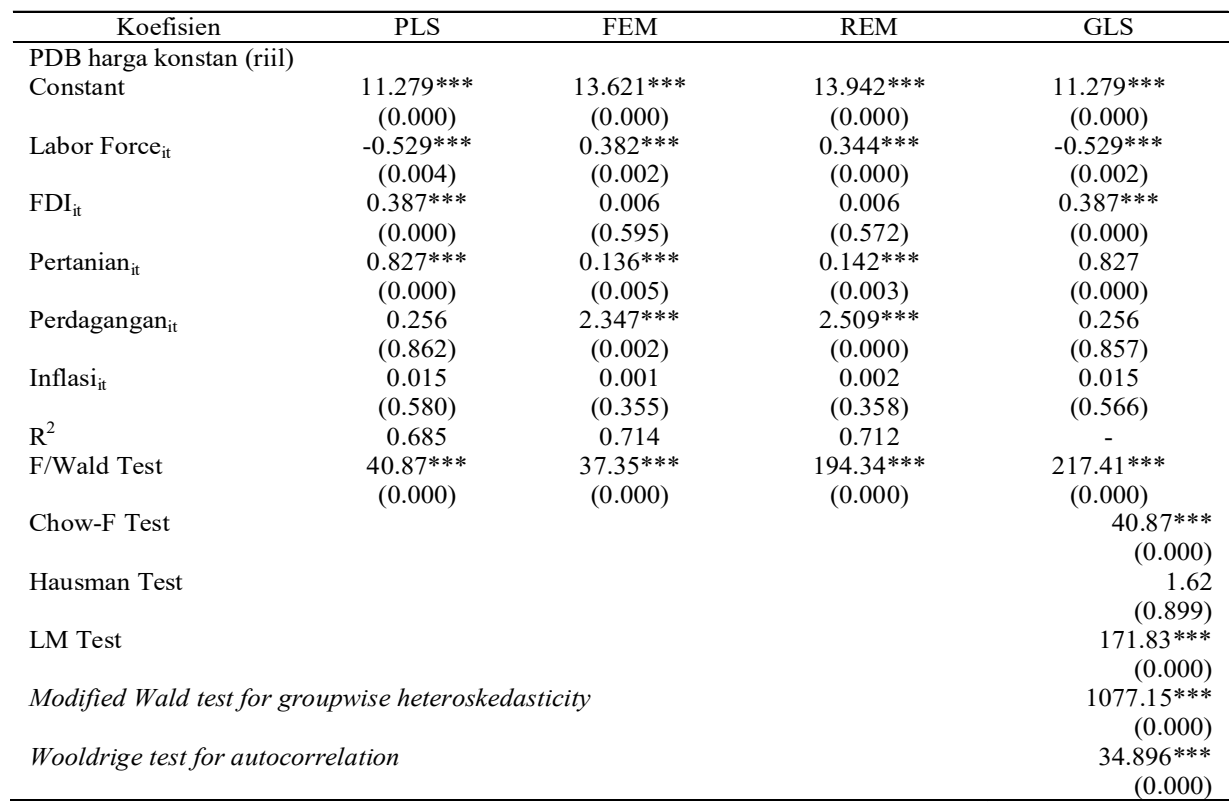


Keterangan: $\quad * * *$ signifikan pada taraf $1 \%$

** signifikan pada taraf 5\%

*signifikan pada taraf $10 \%$

( ) menyatakan P-value

Menurut Pindyck dan Rubinfeld (1998), gejala heteroskedastisitas dan autokorelasi tidak mempengaruhi validitas model, artinya model masih bersifat tidak bias dan konsisten, hanya saja penduga yang dihasilkan tidak efisien. Untuk mengatasi gejala tersebut, maka digunakan pendekatan GLS yang dapat mengakomodasi keberadaan autokorelasi dan heteroskedastisitas pada model panel data. Hasil estimasi model dengan pendekatan GLS memberikan hasil yang cukup baik. Hal ini dapat dilihat dari nilai statistik uji F/Wald yang tinggi yakni sebesar 217,41 yang signifikan pada taraf nyata 1 persen. Nilai tersebut menjelaskan bahwa variabel independen yang digunakan dalam model secara bersama-sama mempengaruhi pertumbuhan ekonomi. Jika dilihat secara satu per satu, variabel labor force, FDI, pertanian, perdagangan, dan inflasi berpengaruh nyata terhadap pertumbuhan ekonomi. Akan tetapi untuk variabel FDI dan inflasi hanya signifikan pada model $P L S$ dan $G L S$. Selanjutnya, uji parsial dari setiap variabel independen beserta pembahasan dari sisi teori dan penelitian terdahulu dijelaskan berikut ini.

\section{Faktor yang berpengaruh terhadap pertumbuhan ekonomi}

Berdasarkan tabel sebelumnya, variabel labor force berpengaruh signifikan terhadap pertumbuhan ekonomi di negara OKI dengan hubungan yang positif. Jadi setiap kenaikan tenaga kerja sebesar 1 persen maka akan meningkatkan pertumbuhan ekonomi sebesar 0,382 persen. Sebaliknya jika setiap penurunan tenaga kerja sebesar 1 persen maka akan menurunkan pertumbuhan ekonomi sebesar 0,382 persen (ceteris paribus). Hal ini sesuai dengan teori yang dipaparkan oleh Todaro (2000) yakni pertumbuhan tenaga kerja merupakan salah satu faktor positif yang dapat memacu pertumbuhan ekonomi. Jumlah tenaga kerja yang bekerja merupakan gambaran kondisi dari lapangan kerja yang tersedia. Semakin bertambah besar lapangan kerja maka akan semakin bertambah pula tenaga kerja dan akan menyebabkan semakin meningkatnya total produksi di suatu daerah. Selain itu, hasil ini sejalan dengan penelitian Yusuf dan Zainuddin (2011) mengenai tren tenaga 
kerja di beberapa negara OKI yang menunjukkan bahwa variabel tenaga kerja berpengaruh secara signifikan terhadap pertumbuhan ekonomi pada sektor industri yang mencatat pertumbuhan tenaga kerja tertinggi sebesar 2,03\% pada tahun 1993-2005.

Variabel Foreign Direct Investmentberdasarkan tabel 4.3 berpengaruh signifikan terhadap pertumbuhan ekonomi di negara OKI dengan hubungan yang positif. Setiap kenaikan FDI sebesar 1 persen maka akan meningkatkan pertumbuhan ekonomi sebesar 0,387 persen. Sebaliknya jika setiap penurunan tenaga kerja sebesar 1 persen maka akan menurunkan pertumbuhan ekonomi sebesar 0,387 persen Hasil tersebut sesuai dengan teori dimana modal sangat berperan dalam menentukan tingkat pertumbuhan ekonomi (Arsyad, 1997). Dalam model pertumbuhan endogen dikatakan bahwa hasil investasi akan semakin tinggi bila produksi agregat suatu negara semakin besar. Hasil penelitian Asghar, Nasreen, dan Rehman (2011) juga menyatakan bahwa foreign direct investment berpengaruh positif terhadap pertumbuhan ekonomi di beberapa negara Asia antara lain Malaysia, Nepal, Singapura, Jepang, dan Bangladesh.

Variabel pertanian berpengaruh signifikan terhadap pertumbuhan ekonomi di negara OKI dengan hubungan yang positif. Jadi setiap kenaikan tenaga kerja sebesar 1 persen maka akan meningkatkan pertumbuhan ekonomi sebesar 0,827 persen. Sebaliknya jika setiap penurunan tenaga kerja sebesar 1 persen maka akan menurunkan pertumbuhan ekonomi sebesar 0.827 persen. Peran pertanian menurut Gwartney (2008) berkontribusi pada pembangunansebagai sebuah aktivitas ekonomi, matapencaharian dan sebagai cara untukmelestarikan lingkungan, sehingga sektor inisebuah instrumen yang unik bagi pembangunan.Sebagai aktivitas ekonomi, pertanian dapat berperan sebagai sumber pertumbuhan bagiperekonomian wilayah, penyedia investasi bagisektor swasta dan sebagai penggerak utamaindustriindustri yang terkait bidang pertanian.Penelitian yang dilakukan oleh Gollin, Parente, dan Rogerson (2002) pada tiga negara yaitu Korea, Malaysia, dan Thailand yang menunjukkan adanya hubungan positif antara pertanian dan pertumbuhan ekonomi di ketiga negara tersebut.

Variabel perdaganganberdasarkan tabel ekonometrik 4.3 berpengaruh signifikan terhadap pertumbuhan ekonomi di negara OKI dengan hubungan 
yang positif. Setiap kenaikan FDI sebesar 1 persen maka akan meningkatkan pertumbuhan ekonomi sebesar 2,509 persen. Sebaliknya jika setiap penurunan tenaga kerja sebesar 1 persen maka akan menurunkan pertumbuhan ekonomi sebesar 2,509 persen. Salvatore (2004) menyatakan bahwa perdagangan dapat menjadi mesin bagi pertumbuhan jika aktivitas perdagangan internasional adalah ekspor dan impor, maka salah satu dari komponen tersebut atau kedua-duanya dapat menjadi motor penggerak bagi pertumbuhan. Hasil ini didukung oleh penelitian Ghani (2011) yang menunjukkan bahwa perdagangan mempengaruhi pertumbuhan ekonomi pada angka GDP per kapita di negara OKI.

Variabel terakhir yaitu inflasi tidak berpengaruh signifikan pada taraf nyata $1 \%, 5 \%$, maupun $10 \%$ terhadap pertumbuhan ekonomi di negara OKI. Namun nilai koefisiennya positif yaitu sebesar 0,002 dengan nilai P-value sebesar 0,528. Hasil ini tidak sesuai dengan hipotesis awal penulis di mana inflasi berpengaruh negatif terhadap pertumbuhan ekonomi. Akan tetapi, hubungan antara inflasi dan pertumbuhanekonomi dijelaskan dalam teori netralitas uang. Menurut Setyowati (2011), pada teori netralitas uang peristiwa-peristiwa di sektormoneter independen dengan peristiwa-peristiwa disektor riil. Dengan demikian, kebijakan pengendalianlaju inflasi (kebijakan di sektor moneter) tidak akanberpengaruh terhadap PDB pada tingkat pertumbuhan ekonomi (sektor riil).

\section{Penut up}

Berdasarkan analisis dan pembahasan yang telah dilakukan pada bab sebelumnya, maka dapat diambil kesimpulan bahwa secara simultan variabel yang digunakan pada penelitian ini berpengaruh signifikan terhadap pertumbuhan ekonomi di negara-negara OKI. Namun, jika dianalisis secara parsial maka dapat diperoleh kesimpulan sebagai berikut:

1. Dari ke-lima variabel yang digunakan, satu variabel tidak berpengaruh secara signifikan terhadap pertumbuhan ekonomi pada 20 negara anggota Organisasi Kerjasama Islam (OKI).

2. Dari hasil koefisien estimasi panel data pada tabel 4.3 model REM dan GLS dapat diketahui dan disimpulkan bahwa: 
a) Variabel tenaga kerja secara signifikan berpengaruh terhadap pertumbuhan ekonomi pada 20 negara anggota OKI.

b) Variabel akumulasi modal secara signifikan berpengaruh terhadap pertumbuhan ekonomi pada 20 negara anggota OKI.

c) Variabel pertanian secara signifikan berpengaruh terhadap pertumbuhan ekonomi pada 20 negara anggota OKI.

d) Variabel perdagangan secara signifikan berpengaruh terhadap pertumbuhan ekonomi pada 20 negara anggota OKI.

e) Variabel inflasi tidak berpengaruh terhadap pertumbuhan ekonomi pada 20 negara anggota OKI.

Berdasarkan analisis penelitian di atas, maka dapat diberikan masukan kepada pengambil kebijakan, yaitu agar dapat meningkatkan pertumbuhan ekonomi seharusnya pemerintah memberikan perhatian lebih kepada sektor pertanian dan perdagangan sebagai sektor yang dapat menopang perekonomian negara OKI, selain itu juga dilakukan upaya peningkatan pertumbuhan ekonomi di masing-masing negara dengan mengandalkan potensi-potensi yang dimiliki serta dapat mengatasi permasalahan pengangguran dengan mempermudah ijin pendirian usaha agar kesempatan kerja semakin besar serta membuka lapangan pekerjaan yang potensial sehingga dapatmenyerap banyak tenaga kerja. Selanjutnya arus FDI yang mengalir ke negara OKI agar dikendalikan dan tidak terkonsentrasi di beberapa negara maju. Terakhir, agar pemerintah membuat kebijakan yang efektif dalam mengkontrol tingkat inflasi. Sehingga diharapkan tingkat pertumbuhan di negara-negara OKI dapat terus meningkat.

\section{Daftar pustaka}

Alpay, S., Atlamaz, M., \& Bakimli, E. (2011). Trade among OIC countries: limits of Islamic solidarity. Insight Turkey, 13(2), 145-170.

Asghar, N., Nasreen, S., \& ur Rehman, H. (2011). Relationship between FDI and economic growth in selected Asian countries: A panel data analysis. Review of Economics \& Finance, 84-96.

Cheong, T. T. (2003). Aggregate Import Demand Function For Eighteen OIC Countries: A Cointegration Analysis. IIUM Journal of Economics and Management. 
Ghani, G. M. (2011). The impact of trade liberalisation on the economic performance of OIC member countries. Journal of Economic Cooperation and Development, 32(1), 1-18.

Gujarati, Damodar. N. (2006). Dasar- Dasar Ekonometrika Jilid I. Diterjemahkan oleh Mulyadi, Julius A. Jakarta: Erlangga.

Gwartney, J., Lawson, R., \& Norton, S. (2008). Economic freedom of the World 2008 annual report. The Fraser Institute

Gollin, D., Parente, S., \& Rogerson, R. (2002). The role of agriculture in development. American Economic Review, 160-164.

Indra. (2009). Analisis Hubungan Intensitas Energi dan Pendapatan Per Kapita: Studi Komparatif di Sepuluh Negara Asia Pasifik. Tesis.

Mohamad, N. H., \& Said, F. B. (2011). Comparing macroeconomic performance of OIC member countries. Management, 1(3), 90-104.

Pindyck, Robert S. dan Rubinfeld, Daniel L. (1998). Econometric Models and Economic Forecast. $4^{\text {th }}$ edition. Singapore: McGraw Hill

Salvatore, D. (2004). Growth and poverty in a globalizing world. Journal of Policy Modeling, 26(4), 543-551.

Setyowati, E. (2011). Analisis Empiris Netralitas Uang Di Indonesia. Jurnal Akuntansi \& Manajemen (JAM), 181.

Sutawijaya, Adrian. (2007). Pengaruh Ekspor dan Investasi terhadap Pertumbuhan Ekonomi Indonesia Tahun 1980-2006. Jakarta: LPPM Universitas Terbuka.

Yusuf, S. A., \& Zainuddin, Z. A. (2011). Trends on Employment and Productivity of OIC Member Countries: An Analysis. International Journal of Economics, Management and Accounting, 19(3). 